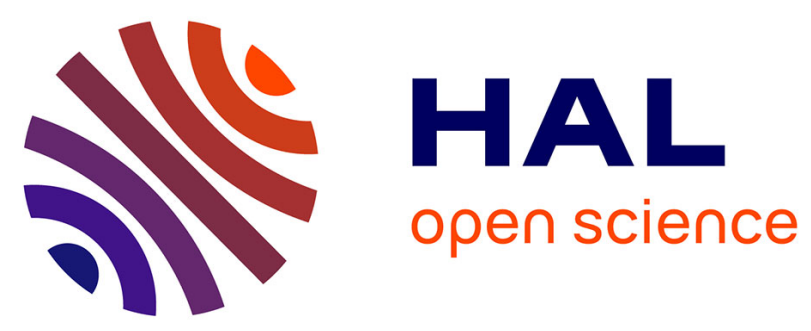

\title{
Combining phase separation with pseudomorphic transformation for the control of the pore architecture of functional materials: A review
}

François Fajula, Anne Galarneau

\section{- To cite this version:}

François Fajula, Anne Galarneau. Combining phase separation with pseudomorphic transformation for the control of the pore architecture of functional materials: A review. Neftekhimiya / Petroleum Chemistry, 2019, 59 (8), pp.761-769. 10.1134/S0965544119080061 . hal-02175323

\section{HAL Id: hal-02175323 \\ https://hal.science/hal-02175323}

Submitted on 25 Nov 2020

HAL is a multi-disciplinary open access archive for the deposit and dissemination of scientific research documents, whether they are published or not. The documents may come from teaching and research institutions in France or abroad, or from public or private research centers.
L'archive ouverte pluridisciplinaire HAL, est destinée au dépôt et à la diffusion de documents scientifiques de niveau recherche, publiés ou non, émanant des établissements d'enseignement et de recherche français ou étrangers, des laboratoires publics ou privés. 


\title{
Combining phase separation with pseudomorphic transformation for the control of the pore architecture of functional materials:
}

\section{A review.}

\author{
François Fajula and Anne Galarneau \\ Institut Charles Gerhardt Montpellier \\ University of Montpellier, ENSCM, CNRS, Place E. Bataillon, 34095 Montpellier France \\ e-mail:ffajula@enscm.fr,anne.galarneau@enscm.fr
}

\begin{abstract}
Chemical phase separation and pseudomorphic transformation are very powerful tools for fine tuning the porous architecture of inorganic oxides. In this short review the basic principles of the preparation of centimetric bodies made of zeolites is introduced. The synthesis of monoliths with homogeneous distributions of interconnected macropores with skeleton made of SOD, LTA and FAU crystals is described. Their unique hierarchical porous texture featuring the structural micropores, intercrystalline mesopores and flow-through macropores leads to remarkable hydrodynamic behavior in separation, catalysis and ion exchange processes operated in continuous-flow mode. In the base-catalyzed carbon-carbon bond formation, productivities twice those achievable with fixed-beds of packed particles are observed. In the capture of strontium present in radioactive effluents their efficiency is three orders of magnitude that of traditional powder in batch.
\end{abstract}

Key words: Spinodal separation, pseudomorphic crystallization, monolitic hierarchical zeolites, catalysis, strontium capture.

\section{Introduction}

The control of the pore architecture of inorganic materials is of paramount importance for the optimization and intensification of most processes operated in continuous flow mode in the fields of catalysis, adsorption or separation [1] and for applications requiring selfstanding bodies [2, 3] with tunable and controlled pore sizes such as Li-ion batteries [4] or super thermal insulators $[5,6]$. Over the years many synthesis and post-synthesis strategies, involving possibly the use of reusable or sacrificial porogens, have been developed to address this challenge. In the frame of our research activities aiming at producing catalysts and sorbents with improved mass transfer characteristics we have explored an original approach 
enabling, not only to precisely tune the textural features of the materials but also to cope with the macroscopic shape constraints attached to their uses. This strategy is based on a combination of chemical spinodal phase separation, to produce monolithic centimetric macroporous bodies with flow through interconnected homogeneous macropores, and pseudomorphic transformation to generate secondary networks of homogeneous and ordered mesopores and/or micropores in the rigid skeleton of the monoliths, generating a large and readily functionalizable active surface. In this review we will introduce the basic principles underlying the chemistry involved in the preparation and modification of these materials, we will describe their physico-chemical properties and highlight their performances in some applications.

\section{Spinodal phase separation}

Chemical phase separation has been used for the first time by the group of Nakanishi in Kyoto [7, 8] for producing silica chromatographic columns featuring a network of flowthrough macropores with a narrow pore size distribution adjustable between 2 and $10 \mu \mathrm{m}$ and diffusive mesopores in the skeleton struts with sizes adjustable in the range $6-20 \mathrm{~nm}$. Compared to classical packed-bed columns, they combine enhanced mass transfer, lower pressure drop and higher separation efficiency owing to a high hydrolytic permeability and short diffusion path lengths. For instance, monoliths with a macropore diameter and skeleton thickness of $2 \mu \mathrm{m}$ demonstrated the same efficiency as beds of particles of $3 \mu \mathrm{m}$ (plate height, $H_{\min }=11 \mu \mathrm{m}$ ) but with a pressure drop of only $2 \mathrm{bar} / \mathrm{cm}$ instead of $35 \mathrm{bar} / \mathrm{cm}$, thus allowing much higher flow rates for ultrafast separation [9]. These materials have been commercialized by Merck in the 2000's under the names of Chromolith for macroscopic pieces or Chromolith CapRod for capillary columns.

Silica monoliths are formed by two concurrent processes, namely a phase separation between silicates and water promoted by a polymer additive and a hydrolytic sol-gel condensation in acid medium. The organic polymer (usually a polyethylene oxide chain) induces the destabilization, and the phase separation, of the initial silicate oligomers-water system by decreasing the hydrophilicity of the silicates and increasing the replusive forces during silicate polymerization. The phase separation is then frozen by a sol-gel transition which kinetics are controlled by the temperature or the amount of water and acid (Fig. 1). 

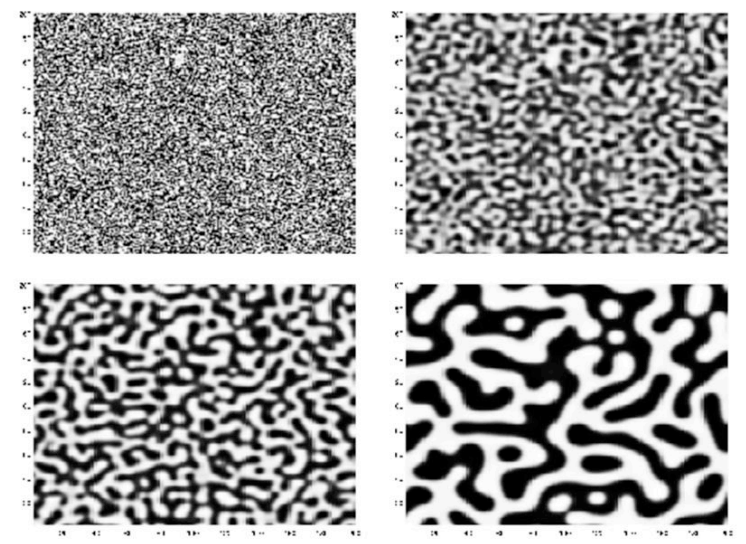

Fig. 1: Schematic representation of a spinodal-phase separation [10]

After the acid step, the resulting monolith features a narrow distribution of macropores, and a poorly condensed silica skeleton. To consolidate the later a post-treatment in mild alkaline conditions is performed (usually in ammonia solution), which leads to the generation of a secondary network of mesopores with diameters adjustable in the range 6 to $20 \mathrm{~nm}[11,12,13]$. Calcined silica monoliths feature a remarkable mechanical strength. Thus a material (Fig. 2) with $5 \mu \mathrm{m}$ macropores, a macropore volume of $2 \mathrm{~mL} / \mathrm{g}$, a surface area of $700 \mathrm{~m}^{2} / \mathrm{g}$, and a mesoporous network consisting of $10 \mathrm{~nm}$ mesopore diameters and a mesopore volume of $1 \mathrm{~mL} / \mathrm{g}$ showed a flexural strength of $0.96 \mathrm{MPa}$ and a compressive strength of 2.67 MPa [14]. To date, the chemical spinodal phase separation procedure has been employed successfully to prepare macroporous monoliths with flow through interconnected macropores made of alumina [15], titania [16, 17], zirconium phosphate [18], polysilsesquioxanes [19], magnesium oxide [20], iron oxide [21].

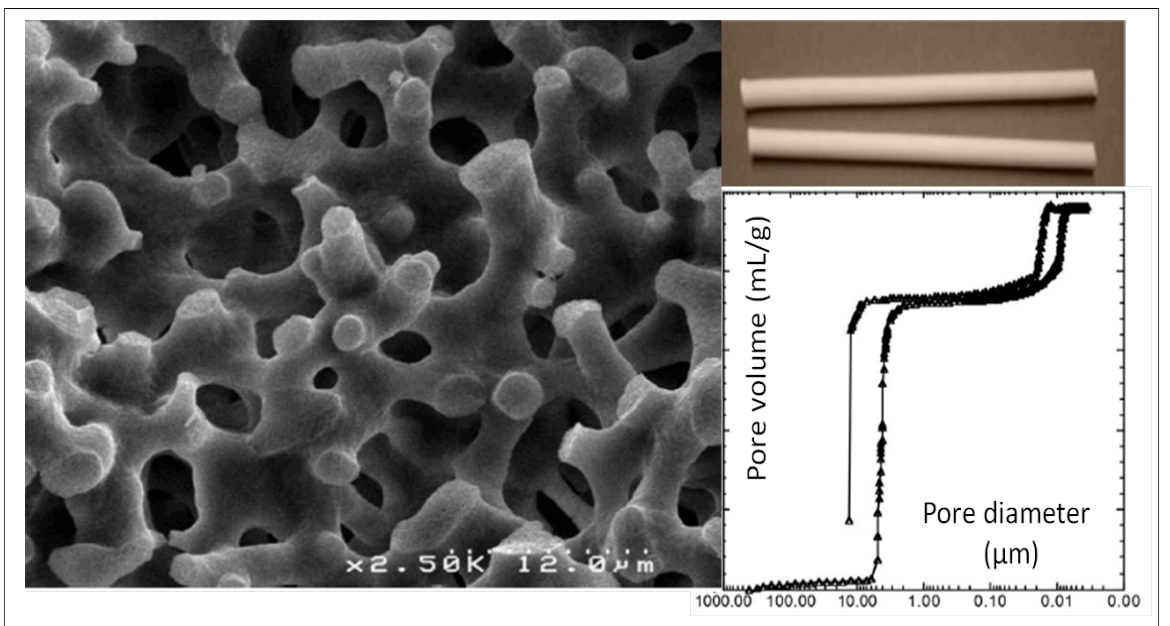

Fig. 2. SEM picture, photograph and mercury porosimetry (two intrusion/extrusion cycles up to 4000 bar) of silica monoliths $(0.6 \mathrm{~cm} \mathrm{x} 10 \mathrm{~cm})$ with macropores of $5 \mu \mathrm{m}$ and mesopores of $10 \mathrm{~nm}$ diameters. 
Besides separation, the unique textural and structural features of these materials, and more particularly their high and accessible surface area, offer significant potential for catalysis. The interskeleton macropores enable high pressure-driven flows leading to fast transport of reactants and products while the intraskeleton mesopores provide extended surface to active sites readily accessed by diffusion. Moreover, compared to traditional packed-beds of porous particles, microreactors consisting in pore-flow-through monoliths favor enhanced exchange between the moving and adsorbed phases, with minimal, if any stagnant fluid, and homogeneous contact times within the catalytic beds. These aspects, and the versatility of the surface activation of silica monoliths, have been illustrated in the catalytic synthesis of fine chemicals. For instance, monoliths functionalized with organosilanes or inorganic precursors operated in continuous flow mode allowed productivities and selectivities significantly larger than fixed bed and batch reactors in the Knoevenagel condensation (with grafted amino groups), the transesterification of triacetine (with grafted sulfonic groups), the Diels-Alder addition (with alumina deposited on the surface), the Friedländer reaction (with occluded CuBTC MOF nanoparticles) and the selective hydrogenation of alcynes (with deposited Pd nanoparticles) [1, 20, 21, 22, 23,24, 25]. More recently $\mathrm{C}-\mathrm{N}$ doped monolithic titanium oxide photocatalysts revealed a remarkable potential for the continuous flow treatment of wastewater under visible light [27]. With these liquid-solid catalytic systems, optimal catalytic performance was achieved with materials with $5 \mu \mathrm{m}$ macropores and 2-3 $\mu \mathrm{m}$ skeleton walls and a ratio monolith diameter to monolith length 1:5 or above [1,24]. Monoliths proved also very efficient as supports, for enzyme immobilization, with for instance 1000 times enhanced productivities compared to the native enzyme for the transformation of sucrose to glucose and fructose [28] and for ionic liquids confinement for the removal of aromatic sulfur compounds from fuels [29].

A further benefit of the unique characteristics of the silica monoliths is the ability of their skeleton to be re-engineered into more ordered porous systems, involving ordered mesoporous structutres and zeolites, while preserving the macroporous architecture. This is achieved by a pseudomorphic transformation of the original silica skeleton, as addressed below.

\section{Pseudomorphic transformation}

Pseudomorphism is a common phenomenon in the mineral world; it corresponds to the precipitation of an altered mineral with a morphology unrelated to its crystallographic symmetry by dissolution of a parent mineral [30,31]. The resulting material, called a 
pseudomorph, assumes the outward crystal morphology of the parent one. The transformation occurs at a non constant matter content by reaction of a mineralizing solution that exchanges cations and/or anions with the existing mineral and allows precipitation of the new structure. In nature, pseudomorphic transformation is a slow process controlled by the rates of water infiltration and soil erosion. Our first attempts to use pseudomorphism for the preparation of materials with ordered porosities and pre-defined shapes were directed to the synthesis of ordered mesoporous materials [32, 33, 34]. Preshaped silica and silica-alumina particles (5 $800 \mu \mathrm{m}$ particle sizes) were gradually locally dissolved and then re-precipitated into MCM-41 materials with the same morphology using the templating effect of surfactant micelles (Fig. 3). The key point in preserving the morphology of the parent silica particles during the transformation process is to tune the rate of mesostructure precipitation to that of silica dissolution. As soon as some silicates species become available they should re-precipitate into MCM-41. Alkalinity, dilution, nature and amount of surfactants, temperature and the presence of auxiliary swelling agents must be thus adapted to the composition and porosity of the parent solid $[35,36]$. Moreover, fine control of the kinetics of the transformation allowed to prepare beads of MCM-48 by a double pseudomorphic transformation of native beads of MCM-41 [34].

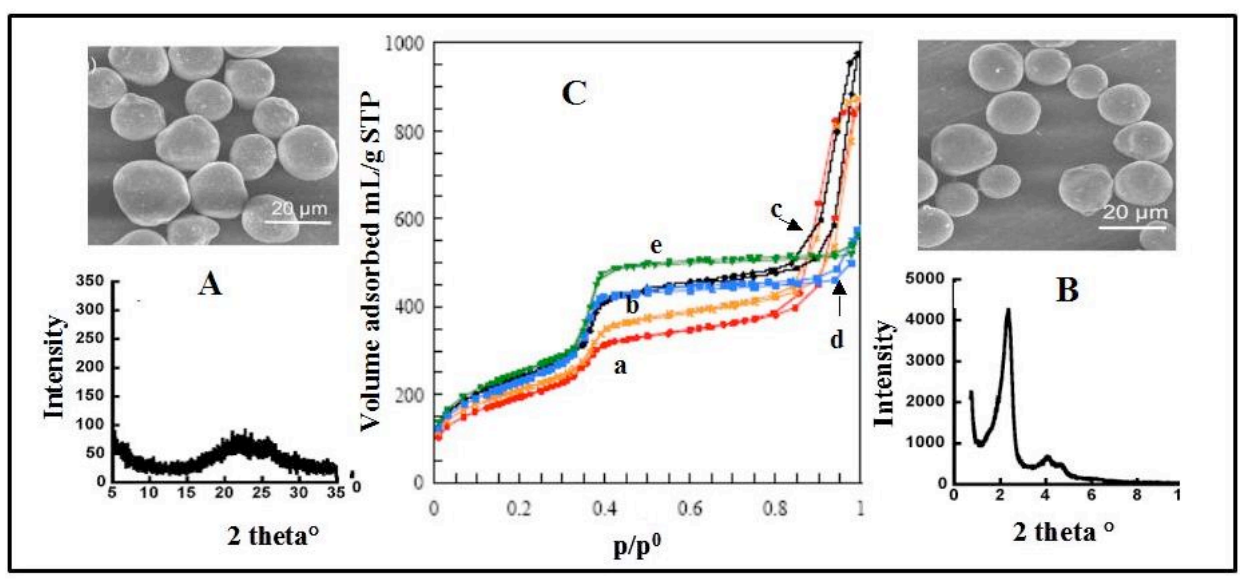

Fig. 3. Pseudomorphic transformation of silica beads (LiChrospher 100, from Merck) into MCM-41. A and B: SEM images and XRD patterns for the LiChrospher and MCM-41, respectively. $\mathrm{C}$ : Nitrogen isotherms at $77 \mathrm{~K}$ for the calcined product recovered after a) $15 \mathrm{~min}$, b) $30 \mathrm{~min}, \mathrm{c}) 1 \mathrm{~h}, \mathrm{~d}$ ) 1 day and e) 6 days of transformation (Adapted from ref. [32]).

The properties of beads (5 and $10 \mu \mathrm{m}$ diameter) MCM-41 and MCM-48 pseudomorphs functionalized with octyl chains have been evaluated as stationary phases for normal and reversed-phase liquid chromatography using mixtures of alkylbenzenes, dibutyl and diethyl-phtalates as solutes. Compared to benchmarck commercial materials with the 
same sizes, mesostructured silicas exhibited increased retentions factors enabling separation of poorly retained solutes not achievable with traditional supports [37, 38].

Regarding the pseudomorphism crystallization of zeolites, the procedure has been used for long, initially with the objective of reducing possible deleterious impact of binders or to provide mechanical strength in catalysts and sorbents [see eg. 39, 40, 41, 42, 43]. More recently pseudomorphism has been used to produce materials with hierarchical distributions of pores, from macro to micropores, using diatomeous earths [44, 45, 46] or structured monoliths $[47,48]$ as parent bodies. Combining chemical phase separation with pseudomorphic transformation has now opened a new, versatile and very powerful route towards a fine tuning of the structural and textural features of functional porous materials. This will be illustrated in the following.

\section{Zeolites with hierarchical porosity produced by spinodal phase separation and pseudomorphic crystallization.}

\subsection{Sodalite monoliths}

Pseudomorphic transformation of the amorphous silica skeleton of macroporous monoliths into zeolites proved very powerful for the binderless shaping of zeolite nanocrystals. First attempts were made for the production of inorganic stable and efficient basic solid catalysts for process intensification by crystallization of the amorphous skeleton of a silica monolith (hereafter MonoSil) into sodalite (MonoSil-SOD) [49]. Because of the small size of its pore apertures (flexible aperture between 0.20 to $0.28 \mathrm{~nm}$ [50]), sodalite is hardly considered as a catalyst. However, Shanbhag et al [51] showed that sodalite with a hierarchical mesoporous/microporous structure synthesized using an organosilane surfactant exhibited a higher basicity and a much higher catalytic activity than that of CsNaX or KAlMCM-41 for various base catalyzed reactions involving bulky and small substrates, such as Knoevenagel condensation, Claisen-Schmidt condensation in liquid phase, and acetonylacetone cyclization in vapor phase. Interestingly the catalyst showed longer lifetime than $\mathrm{CsNaX}$ and KAlMCM41.

A parent MonoSil $(7.8 \mathrm{~cm}$ length, $6.14 \mathrm{~mm}$ diameter, $6 \mu \mathrm{m}$ macropores, $3 \mu \mathrm{m}$ skeleton thickness, macropore volume $1.75 \mathrm{~mL} / \mathrm{g}$, surface area $750 \mathrm{~m}^{2} / \mathrm{g}, 7 \mathrm{~nm}$ mesopore diameter, mesopore volume $0.96 \mathrm{~mL} / \mathrm{g}$ ) was impregnated with an alkaline solution of sodium aluminate and tetrapropylammonium hydroxyde to achieve a molar composition of $1 \mathrm{SiO}_{2} / 0.15$ $\mathrm{NaOH} / 2.6 \mathrm{NaAlO}_{2} / 33 \mathrm{H}_{2} \mathrm{O} / 0.004 \mathrm{TPAOH}$ in a Teflon-lined stainless steel autoclave which was hydrothermally treated at $150{ }^{\circ} \mathrm{C}$ for 18 hours. The recovered monolith, washed and 
calcined at $550{ }^{\circ} \mathrm{C}$ for $8 \mathrm{~h}$, preserved its macroscopic shape and exhibited the XRD pattern of pure sodalite. ${ }^{29} \mathrm{Si}$ NMR and ${ }^{27} \mathrm{Al}$ NMR spectra featured single peaks (at -91 and $59 \mathrm{ppm}$, respectively) characteristic of $\mathrm{SOD}$ with $\mathrm{Si} / \mathrm{Al}=1$. SEM images (Fig. 4) showed the preservation of the macroporous network, with the amorphous skeleton of the original monolith transformed into an aggregation of crystals of 0.5 to $1.5 \mu \mathrm{m}$ in size.

Mercury porosimetry and nitrogen sorption revealed a macroporous network of uniform size around $3 \mu \mathrm{m}$ with a macroporous volume of $1.00 \mathrm{~mL} \mathrm{~g}^{-1}$ (or $0.34 \mathrm{~mL} / \mathrm{cm}^{3}$ of monolith in comparison to $0.47 \mathrm{~mL} / \mathrm{cm}^{3}$ for original MonoSil). The smaller macropore volume per unit volume of monolith results from the growth of the SOD crystals. Large secondary pores between 4 to $100 \mathrm{~nm}$ are identified by the upper volume uptake in mercury porosimetry $(0.07$ $\mathrm{mL} \mathrm{g}^{-1}$ ) and by the vertical hysteresis loop above $0.8 \mathrm{P} / \mathrm{P}_{0}$ in nitrogen isotherm revealing intercrystalline pores between crystals and embedded inside the SOD crystals.
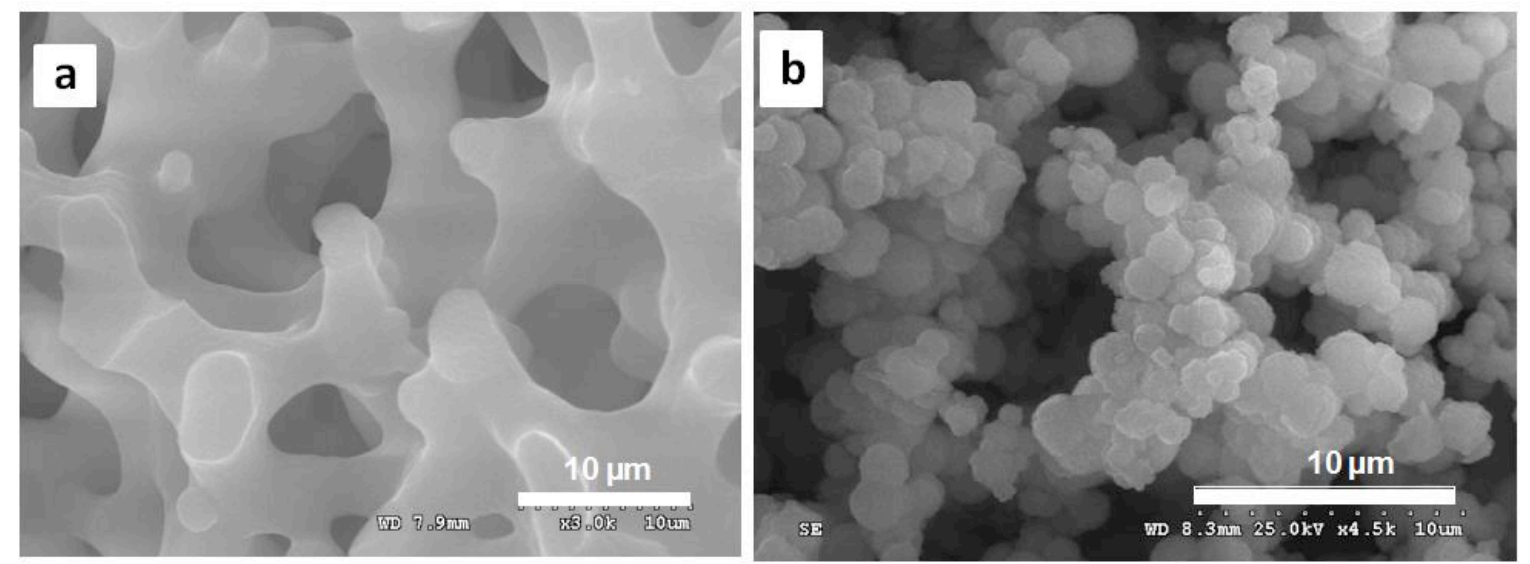

Fig. 4. SEM images of a) the parent silica monolith and of b) its pseudomorphic transformation into Sodalite.

The MonoSil-SOD was cut into $1 \mathrm{~cm}$ pieces and cladded with a heat-shrinkable DERAYPTFE gain to be mounted in a recirculating flow system (Fig. 5). The $\mathrm{Na}^{+}$cations present in as-synthesized MonoSil-SOD were exchanged by $\mathrm{K}^{+}$cations (91\% exchange) by circulating a $\mathrm{KCl}$ solution through the microreactor. After washing with water and activation at $140^{\circ} \mathrm{C}$ under reduced pressure the Knoevenagel condensation was performed at $80^{\circ} \mathrm{C}$ with a contact time of 2 min between 4-isopropylbenzaldehyde (4-IPB) and ethylcyanoacetate (ECA) to give 4-isopropylstyrylethyl-cyanoacetate. 


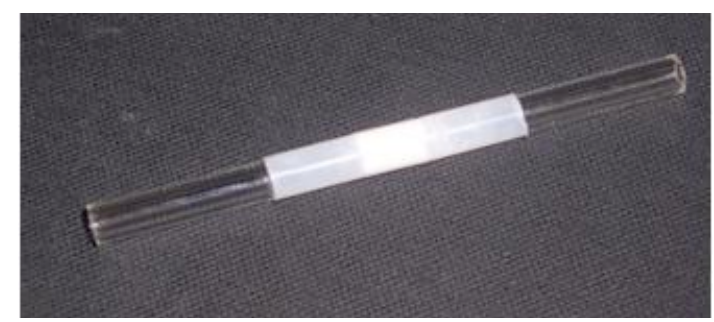

Fig. 5. Picture of a cladded MonoSil-SOD $(0.6 \times 1 \mathrm{~cm})$ with glass connections.

A steady state conversion of $65 \%$ was reached after 5 min on stream with no loss of activity during at least $200 \mathrm{~h}$ in flow. Interestigly the productivity of the MonoSil-SOD catalyst, were only the external surface $\left(12 \mathrm{~m}^{2} / \mathrm{g}\right)$ is operative for the reaction, was twice that of packed-bed reactors filled with 50-100 $\mu \mathrm{m}$ particles of crushed monolith.

\subsection{LTA monoliths}

LTA-monoliths (MonoSil-LTA) with skeletons formed by an association of faceted cubic- like crystals with a broad distribution of sizes in the range $0.2-1.5 \mu \mathrm{m}$ together with 1 $\mu \mathrm{m}$ spherical microcrystals were obtained by pseudomorphic transformation of parent silica monoliths prepared by using PEO polymers of either $20 \mathrm{kDa}$ (macropores $5 \mu \mathrm{m}$, skeleton thickness $3 \mu \mathrm{m}$ ) or $35 \mathrm{kDa}$ (macropore $11 \mu \mathrm{m}$, skeleton thickness $7 \mu \mathrm{m}$ ) at $100{ }^{\circ} \mathrm{C}$ for $24 \mathrm{~h}$ using a mixture with the overall molar ratio: $1 \mathrm{SiO}_{2} / 0.15 \mathrm{NaOH} / 2.6 \mathrm{NaAlO}_{2} / 33 \mathrm{H} \mathrm{H}_{2} \mathrm{O} / 0.004$ TPAOH [52]. Compared to classical procedures used for LTA synthesis [53] a lower amount of $\mathrm{NaOH}$ and a higher amount of aluminum were engaged in the crystallization mixture to slow down the rate of dissolution of the parent MonoSil in order to preserve the monolithic skeleton structure during its transformation into LTA. The micropore volume of the MonoSilLTA pseudomorph after ion exchange with calcium cations in order to allow access of nitrogen to the structural micropores was equal to $0.18 \mathrm{~mL} / \mathrm{g}$ indicating that MonoSil-LTA consisted in at least $70 \mathrm{wt} \%$ of zeolite. As previously described for MonoSil-SOD, a basic MonoSil-LTA catalyst microreactor was prepared by exchanging the sodium cations by potassium cations ( $85 \%$ exchage) and evaluated in the Knoevenagel condensation reaction. At contact times of $2 \mathrm{~min}$ and $5 \mathrm{~min}$, steady state conversions of $55 \%$ and $99 \%$, respectively, were obtained, with no loss of activity after 20 hours on stream.

MonoSil-LTA has been evaluated for the removal of radioactive cations from complex aqueous effluents mimicking contaminated seawater effluents of the Fukushima case. Traditional zeolite-based procedures for the selective removal of $\mathrm{Cs}^{+}$and $\mathrm{Sr}^{2+}$ generate huge volumes of contaminated waste and give rise to severe health hazards due to the handling of 
powders. A MonoSil-LTA has been used for the continuous-flow removal of $\mathrm{Sr}^{2+}(10 \mathrm{mg} / \mathrm{L})$ contained in a solution of sodium chloride $(0.1 \mathrm{M})$ at flow rates of 0.5 and $0.15 \mathrm{~mL} / \mathrm{min}$ (Fig. 6). At the lower flow rate, the breakthrough curve shows a complete retention of strontium amounting to $0.37 \mathrm{mmol} / \mathrm{g}$ and a total exchange capacity of $0.86 \mathrm{mmol} / \mathrm{g}$ (Fig. 6). Under the same conditions, ion-exchange resins retained merely $0.05 \mathrm{mmol} / \mathrm{g}$ whereas in batch experiments, LTA powder retained only $0.22 \mathrm{mmol} / \mathrm{g}$ after $24 \mathrm{~h} \mathrm{[54].}$

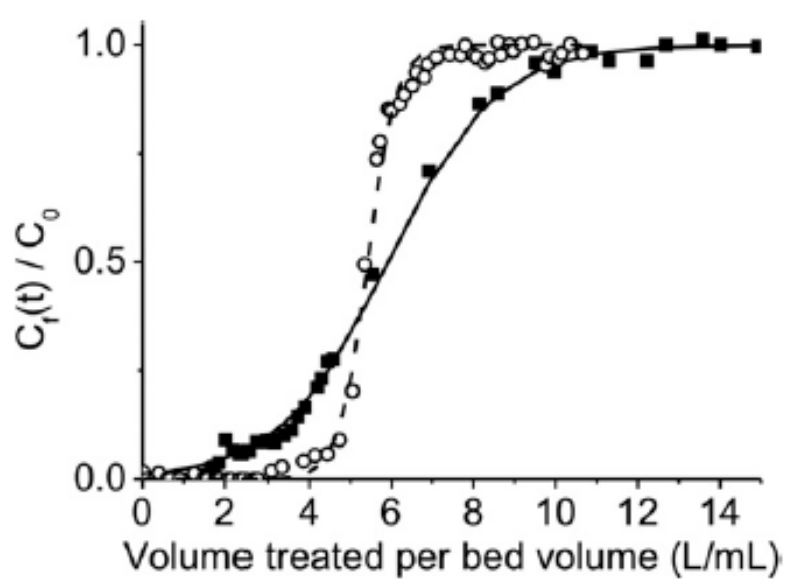

Fig. 6. Breakthrough curves for MonoSil-LTA for an initial $\mathrm{Sr}^{2+}$ concentration of $10 \mathrm{mg} / \mathrm{L}$ in a $0.1 \mathrm{M}$ solution of $\mathrm{NaCl}$. Filled squares $0.5 \mathrm{~mL} / \mathrm{min}$, open circles $0.15 \mathrm{~mL} / \mathrm{min}$.

Experiments were then performed using a simulated Fukushima seawater containing radioactive ${ }^{90} \mathrm{Sr}^{+}(5.5 \mathrm{ng} / \mathrm{L}, 28 \mathrm{kBq} / \mathrm{L})$ in the presence of large amounts of several competing cations $\left(\mathrm{Na}^{+} 9.6 \mathrm{~g} / \mathrm{L}, \mathrm{Mg}^{2+} 1.28 \mathrm{~g} / \mathrm{L}, \mathrm{Ca}^{2+} 0.4 \mathrm{~g} / \mathrm{L}, \mathrm{K}^{+} 0.5 \mathrm{~g} / 1\right.$ non radioactive $\left.\mathrm{Sr}^{+} 0.008 \mathrm{~g} / \mathrm{L}\right)$. Compared to LTA powder in batch, the MonoSil-LTA was able to process 4 times more volume of the highly salty radioactive solution per unit of mass and allowed to reach much higher decontamination levels with the additional benefit of a significant safety improvement. In depth analysis of the above data revealed that the overall efficiency of the decontamination process could be significantly enhanced - particularly for high flow rates - by improving the transfer of the fluid through the monolith skeleton and, consequently, the kinetics of the of ion exchange reaction. Introducing intercrystalline mesopores and decreasing the size of the crystals have been therefore attempted. The methodology used consisted in separating the nucleation and crystallization steps of the pseudomorphic transformation [55].

Silica monoliths (6 $\mathrm{mm}$ diameter, 5 or $10 \mathrm{~cm}$ length) with hierarchical porosity (macropore diameter $5 \mu \mathrm{m}$, macropore volume $2 \mathrm{~mL} / \mathrm{g}$, mesopore diameter $13 \mathrm{~nm}$, mesopore volume $1 \mathrm{~mL} / \mathrm{g}$ ) were used as starting materials. The monoliths were soaked in an alcaline 
aluminate solution with the overall composition indicated above which was aged for $24 \mathrm{~h}$ at $40{ }^{\circ} \mathrm{C}$. The amorphous skeleton of MonoSil was then crystallized into LTA at $70{ }^{\circ} \mathrm{C}$ for $24 \mathrm{~h}$. SEM images (Fig. 7) reveal a uniform macroporous network of $c a 4 \mu \mathrm{m}$ and a skeleton thickness of $c a 2.5 \mu \mathrm{m}$ formed by an aggregation of nanocrystals of 300-500 $\mathrm{nm}$ at the outer surface and of $100 \mathrm{~nm}$ in the core. This MonoSil-LTA consists of $c a 95 \mathrm{wt} \%$ of zeolite LTA and features a uniform hierarchical trimodal porosity with structural micropores of $0.4 \mathrm{~nm}$, inter crystal mesopore diameter of $35 \mathrm{~nm}$ and macropore diameter of 4 microns

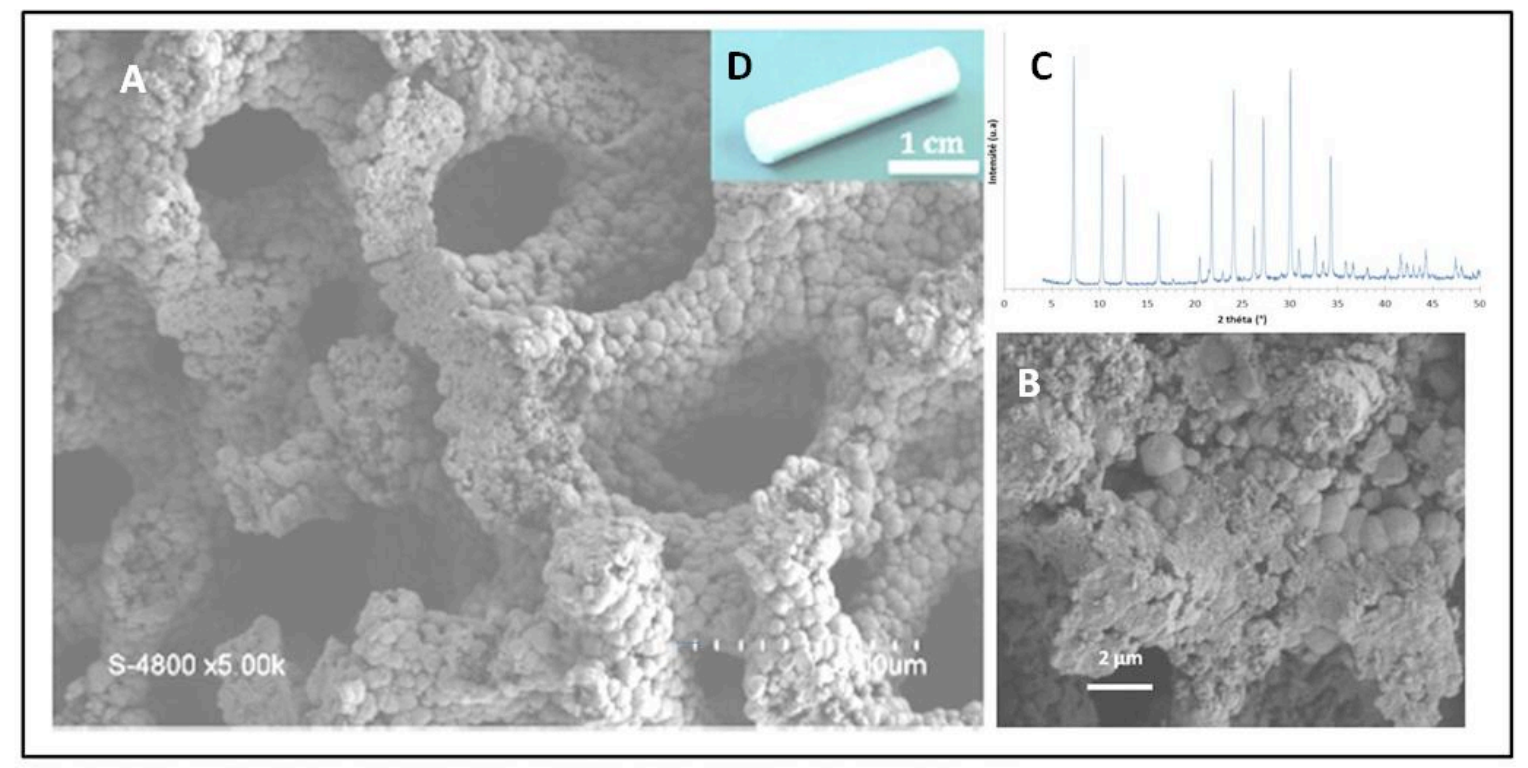

Fig. 7. SEM images (A,B), XRD pattern (C) and photograph (D) of MonoSil-LTA with trimodal porosity.

In the capture of strontium present in salty solutions, the trimodal MonoSil-LTA proved superior to bimodal MonoSil-LTA and 1000 times more efficient than packed beds of LTA powders. Actually 4200 bed volumes (BV) of solution could be treated with $1 \mathrm{~mL}$ of monolith at a flow rate of $34 \mathrm{BV} / \mathrm{h}$ with no trace of $\mathrm{Sr}^{2+}$ detectable by ionic chromatography in the effluent [56].

\subsection{FAU monoliths}

Direct pseudomorphic crystallization of silica monoliths into faujasite X (FAU) by reaction of the parent MonoSil with an alkaline mixture containing the aluminium source could not be achieved as was the case of the preparation of MonoSil-SOD and MonoSil-LTA due to a too fast rate of silica dissolution compared to the rate of FAU crystallization. To 
reach our goal, a double pseudomorphic transformation was operated [57]. MonoSil was first transformed into MonoSil-Al by incorporation of alumina in the silica skeleton. To this end, the silica monoliths have been transformed into silica-alumina monoliths $(0.25<\mathrm{Al} / \mathrm{Si}<$ $0.40)$ at low $\mathrm{NaOH}$ concentration $([\mathrm{NaOH}]=0.24 \mathrm{M})$ at $40{ }^{\circ} \mathrm{C}$ for $24 \mathrm{~h}$. This allowed to decrease the solubility of the original skeleton while preserving the macroscopic structure of the macroporous network. The self-standing binderless FAU-X monoliths (MonoSil-FAU) were then formed at higher $\mathrm{NaOH}$ concentration $([\mathrm{NaOH}]=2.2 \mathrm{M})$ by a two steps crystallization procedure involving an aging period at $40{ }^{\circ} \mathrm{C}$ for 4 days and a crystallization step at $100{ }^{\circ} \mathrm{C}$ for $24 \mathrm{~h}$.

Table 1 summarizes the main physico-chemical characteristics of the monoliths at different stages of the synthesis protocol.

\begin{tabular}{lccccccc}
\hline Monoliths & $\mathrm{V}_{\text {macro }}$ & $\mathrm{V}_{\text {meso }}$ & $\begin{array}{c}\mathrm{V}_{\text {micro }} \\
(\mathrm{mL} / \mathrm{g})\end{array}$ & $\begin{array}{c}\mathrm{D}_{\text {meso }} \\
(\mathrm{mL} / \mathrm{g})\end{array}$ & $\begin{array}{c}\mathrm{S}_{\text {BET }} \\
(\mathrm{mL} / \mathrm{g})\end{array}$ & $\begin{array}{c}\text { Density } \\
\left(\mathrm{m}^{2} / \mathrm{g}\right)\end{array}$ & $\begin{array}{l}\mathrm{Si} / \mathrm{Al} \\
\left(\mathrm{g} / \mathrm{cm}^{3}\right)\end{array}$ \\
\hline MonoSil & 2.0 & 1.20 & - & 10 & 739 & 0.28 & - \\
MonoSil-Al & 1.1 & 0.23 & - & 16 & 57 & 0.52 & 2 \\
MonoSil-FAU & 1.0 & 0.40 & 0.30 & $>30$ & 725 & 0.56 & 1.2
\end{tabular}

Table 1. Physico-chemical characteristics of the monoliths at different stages of the synthesis protocol.

The incorporation of aluminium in silica monolith results in a significant increase of the density of the monolith with a decrease of the intergrain mesoporosity and surface area. After crystallization the micropore volume measured by nitrogen adsorption at $77 \mathrm{~K}$ and the XRD pattern (Fig. 8) indicate that the material consists in more than $90 \%$ FAU zeolite.

Several families of MonoSil-FAU could be produced with this protocol. SEM images (Fig. 8) reveal that MonoSil-FAU feature macropores with diameters adjustable from 3 to $20 \mu \mathrm{m}$ (similar to the parent silica monolith). The skeleton of the FAU-X monoliths is formed by an aggregation of two populations of FAU-X nanocrystals $(100-200 \mathrm{~nm} / 400-500 \mathrm{~nm})$ generating a secondary porosity between the nanocrystals of 30 to $1000 \mathrm{~nm}$ in diameter, centered at $300 \mathrm{~nm}$. MonoSil-FAU materials present therefore three levels of readily 
interconnected porosities with a macropore volume of $c a .1 .0 \mathrm{~mL} / \mathrm{g}$, a secondary pore volume of $c a .0 .40 \mathrm{~mL} / \mathrm{g}$ and a micropore volume of $0.30 \mathrm{~mL} / \mathrm{g}$.

The performances of MonoSil-FAU are being evaluated in the capture and sequestration of Cs ions from contaminated aqueous streams and the separation of xylenes.

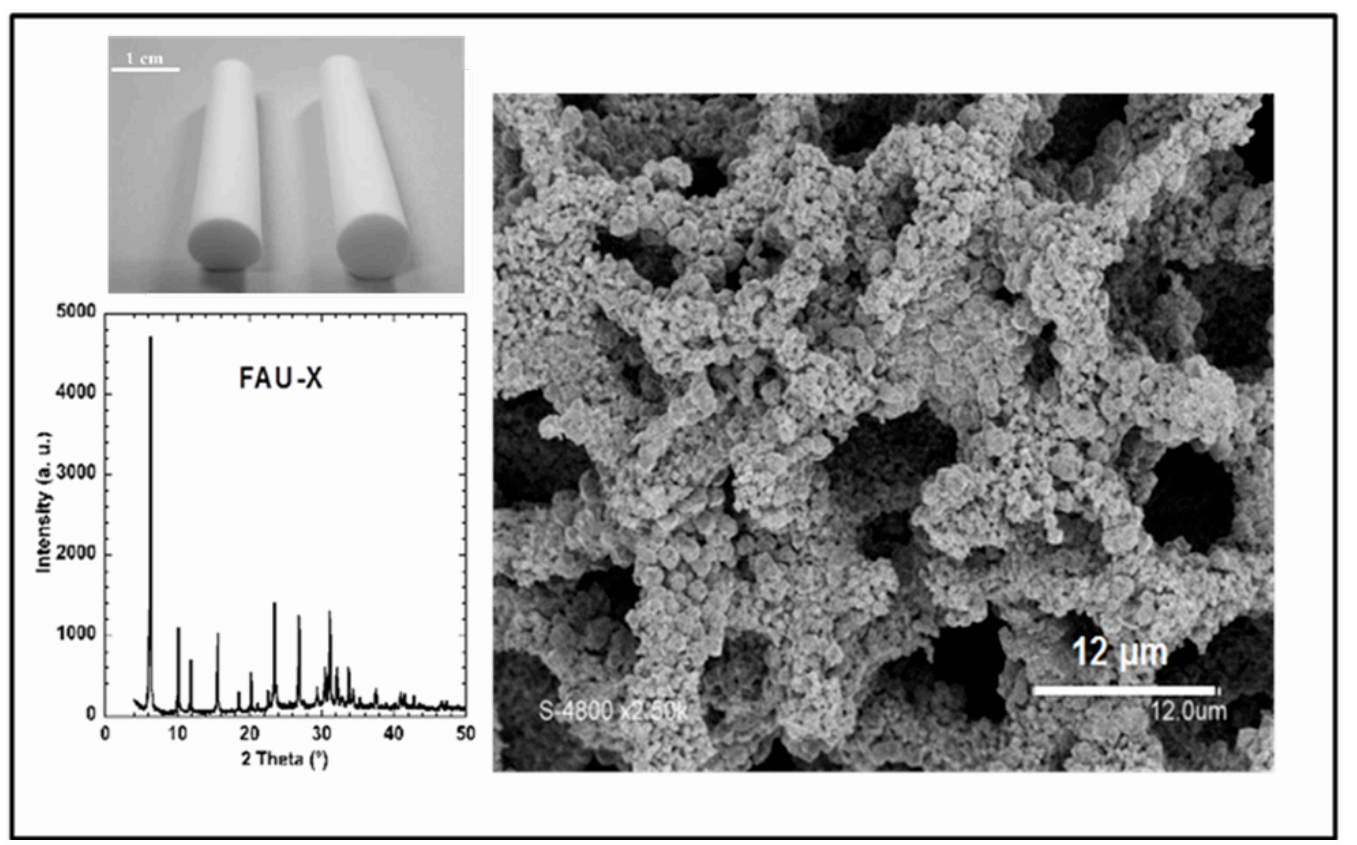

Fig. 8. SEM image, picture and XRD pattern of MonoSil-FAU.

\section{Conclusions}

Laboratory experiments have definitely demonstrated the potential of synthesis strategies based on phase separation and pseudomorphic crystallization for the preparation of materials with tunable hierarchical porosities. The present review highlights how macroporous monoliths with homogeneous and interconnected networks of micro, meso and macropores may contribute to process intensification through textural control and opens very stimulating directions of research. Future efforts should be directed to the production of higher silica zeolites, the scale-up of the procedures and the seamless cladding of the monoliths.

ZSM-5 monoliths featuring large macropores $(>400 \mu \mathrm{m})$ have been obtained using a monolithic polyuretane foam as template. The materials led to higher performance than its pelletized counterpart in the methanol to olefins reaction but with a limited productivity gain however due to the large pores and thick walls. Transformation of MonoSil type monoliths into ZSM-5 has been reported by Lei et al [48] but the material exhibited a very low 
micropore volume $(<0.02 \mathrm{~mL} / \mathrm{g})$ indicating only marginal crystallization. Regarding scale-up, while the production of large tubular species or disks of macroporous silicas by spinodal phase separation is readily achievable, the homogeneous crystallization of their skeleton throughout the whole piece is more tricky as stirring cannot be employed calling for imaginative new procedures. Finally, proper cladding of the monolithic rods to produce self standing reactors or sorbents is very important to expand the fields of applications. The use of thermoshrinking polymers is very convenient and easy to handle at laboratory scale but limits the range of operation conditions to low temperature and low pressure systems. Cladding into stainless-steel tubing using epoxy resin adhesive [58] or chemical resistant cements are alternatives.

Acknowledgments: The authors thank the St Nikon Foundation for constant and stimulating support. 


\section{References}

[1] For a recent review: A. Galarneau, A. Sachse, B. Said, C-H. Pelisson, P. Boscaro, N. Brun, L. Courtheoux, N. Olivi-Tran, B. Coasne, and F. Fajula, C. R. Chimie 19, 231 (2016) .

[2] P.R. Aravind, P. Shajesh, G.D. Soraru, and K.G.K.Warrier, J. sol-Gel Sci. Technol. 54, 105 (2010).

[3] S-W. Hwang, H.-H. Jung, S-H. Hyun, and Y-S. Ahn, J. sol-Gel Sci. Technol. 41, 139 (2007).

[4] A. Guyomard-Lack, B. Said, N. Dupré, A. Galarneau, and J. Le Bideau, New J. Chem., 40, 4269 (2016).

[5] Y. Belmoujahid, M. Bonne, Y. Scudeller, D. Schleich, Y. Grohens, and B. Lebeau, Microporous Mesoporous Mater. 201, 124 (2015).

[6] T-Y. Wei, T.F. Chang, and S.Y. Lu, J. Am. Ceram. Soc. 90, 2003 (2007).

[7] K. Nakanishi, N. Soga, J. Non-Cryst. Solids 1, 139 (1992).

[8] K. Nakanishi, J. Porous Mater. 4, 67 (1997).

[9] T. Tanaka, H. Kobayashi, N. Ishizuka, H. Hosoya, T. Ikegami, J. Chromatogr. A 35, 965 (2002).

[10] https://upload.wikimedia.org/wikipedia/commons/9/9b/CahnHilliard_Animation.gif. released into the public domain by its author, Mcnaknik at English Wikipedia.

[11] K. Nakanishi, H. Shikata, N. Ishizuka, N. Koheiya, N. Soga, J. High. Resolut. Chromatogr. 13, 106 (2000).

[12] A. Galarneau, J. Iapichella, D. Brunel, F. Fajula, Z. Bayram-Hahn, K. Unger, G. Puy, C. Demesmay, J-L. Rocca. J. Sep. Sci. 29, 844 (2006).

[13] G. Puy, R. Roux, C. Demesmay, J-L. Rocca, J. Iapichella, A. Galarneau, D. Brunel, J. Chromatogr. A. 150, 1160 (2007)

[14] A. Galarneau, Z. Abid, B. Said, Y.Didi, K.Szymanska, A. Jarzębski, F. Tancret, H. Hamaizi, A. Bengueddach, F. Di Renzo and F. Fajula, Inorganics 4, 9 (2016).

[15] Y. Tokudome, K.Fujita, K. Nakanishi,K. Miura,and K. Hirao, Chem. Mater. 19, 3393 (2007).

[16] J. Konishi, K. Fujita, K. Nakanishi, K. Hirao, Chem. Mater. 18, 6069 (2006).

[17] N. Linares, S. Hartmann, A. Galarneau, P. Barbaro, ACS Catal. 2, 2194 (2012).

[18] Y. Zhu, T. Shilizu, T. Kitashima, K. Morisato, N. Moitra, N. Brun, K. Kanamori, K. Takeda, M. Tafu, and K. Nakanishi, New J. Chem. 39, 2444 (2015).

[19] K. Kanamori, and K. Nakanishi, J. Mater. Chem. 15, 3776 (2005), Chem. Soc. Rev. 40, 754 (2011).

[20] X. Lu, K. Kanamori, and K Nakanishi, J. Sol-Gel Sci. and technol. 89, 29 (2019)

[21] Y.Hara, K. Kanamori, K. Morisato, R. Miyamoto, and K. Nakanishi, J. Mater. Chem. A 6, 9041 (2018).

[22] A. Sachse, A. Galarneau, B. Coq, and F. Fajula, New J. Chem. 35, 259 (2012).

[23] A. El Kadib, R. Chimenton, A. Sachse, F. Fajula, and A. Galarneau, Angew. Chem. Int. Ed. 48, 4969 (2009).

[24] A. Sachse, V. Hulea, A. Finiels, B. Coq, F. Fajula, and A. Galarneau, J. Catal. 287, 62 (2012)

[25] A. Sachse, R. Ameloot, B. Coq, F. Fajula, B. Coasne, D. De Vos, and A. Galarneau, Chem. Commun. 48, 4749 (2012)

[26] A. Sachse, N.Linares, P. Barbaro, F. Fajula, and A. Galarneau, Dalton Trans. 42 , 1378 (2013). 
[27] P. Boscaro, T. Cacciaguerra, D. Cot, F. Fajula, V. Hulea, and A. Galarneau, Microporous Mesoporous Mat. 280, 37 (2019).

[28] K. Szymanska, W. Pudio, J. Mrowiec-Bialon, A. czardybon, J. Kocurek, and A.B. Jarzebski, Microporous Mesoporous Mater. 170, 75 (2013)

[29] P. Forte, A. Sachse, M. Maes, A. Galarneau, and D. De Vos, RSC Adv. 4, 1045 (2014)

[30] J. Sinlankas, Mineralogy (Van Nostrand Reinhold, New York) 85 (1964)

[31] G.C. Garcia, Bocamina 2, 38 (1996).

[32] T. Martin, A. Galarneau, F. Di Renzo, F. Fajula and D. Plee, Angew. Chem. Int. Ed. 41, 2590 (2002).

[33] B. Lefevre, A. Galarneau, J. Iapichella, C. Petitto, F. Di Renzo, F. Fajula, Z. BayramHahn, R. Skudas and K.K. Unger, Chem. Mater.17, 601 (2005).

[34] C. Petitto, A. Galarneau, M-F. Driole, B. Chiche, B. Alonso, F. Di Renzo and F. Fajula, Chem. Mater. 15, 2120 (2005).

[35] M.F. Ottaviani, A. Moscatelli, D. Desplantier-Giscard, F. Di Renzo, P.J. Kooyman, B. Alonso and A. Galarneau, J. Phys. Chem. B 108, 12123 (2004).

[36] F. Fajula, Dalton Trans 291 (2007).

[37] T. Martin, A. Galarneau, F. Di Renzo, D. Brunel, F. Fajula, S. Heinsich, G. Grettier, and J. L. Rocca, Chem. Mater. 16, 1725 (2004).

[38] A. Galarneau, J. iapichella, D. Brunel, F. Fajula, Z. Bayram-Hahn, K.K. Unger, G. Puy, C. Deesmay and J.L. Rocca, J. Sep. Sci., 29, 844 (2006).

[39] S. M. Brown and G.M. Woltermann, US Patent No 4235753 (1980).

[40] J. P. McWilliams, US Patent No 5145659 (1992).

[41] W. Schwieger, M. Rauscher, F. Scheffer, D. Freude, U. Pingel, and F. Janowski, Proceedings 12th Intern. zeolite Conf., Baltimore, USA, 1849 (1998).

[42] D. Plee, US Patent No 6264881 (2001).

[43] M. Manko, J. Vittenet, J. Rodriguez, D. Cot, J. Mendret, S. Brosillon, W. Makowski and A. Galarneau Microporous Mesoporous Mat. 176, 145 (2013).

[44] M. W. Anderson,S. M. Holmes, N. Hanif and C. S. Cundy, Angew Chem Int Ed Engl. 39, 2707 (2000).

[45] Y. Wang, Y. Tang, A. Dong, X. Wang, N. Ren and Z. Gao, J. Mater. Chem. 6, 1812 (2002).

[46] M. Choi, K. Na and R. Ryoo, Chem. Commun. 2845 (2009)

[47] F. Xia, J. Brugger, Y. Ngothai, B. O’Neill, G. Chen and A. Pring, Cryst. Growth Des. 9, 4902 (2009).

[48] Q. Lei, T. Zhao, F. Li, L. Zhang, Y. Wang, Chem. Commun. 1769 (2006).

[49] A. Sachse, A. Galarneau, F. Di Renzo, F. Fajula, and B. Coq, Chem. Mater. 22, 4123 (2010).

[50] S. R . Lee, Y. H . Son, A. Julbe, and J.H. Choy, Thin Solid Film 92, 495 (2006)

[51] G. V. Shanbhag, M. Choi, J. Kim, and R. Ryoo, J. Catal. 264, 88 (2009).

[52] A. Sachse, A. Galarneau, F. Fajula, F. Di Renzo, P. Creux, and B. Coq, Microporous Mesoporous Mater. 140, 58 (2011).

[53] Verified syntheses of zeolitic materials, Ed. by H. Robson (Elsevier, 2001)

[54] A. Sachse, A. Merceille, Y. Barré, A. Grandjean, F. Fajula, and A. Galarneau, Microporous Mesoporous Mater. 164, 251 (2012)

[55] B. Said, T. Cacciaguera, F.s Fajula, and A. Galarneau, Microporous Mesoporous Mater. 227, 176 (2016).

[56] B. Said, A. Grandjean, Y. Barre, F. Tancret, F. Fajula, and A. Galarneau, Microporous Mesoporous Mater. 232, 39 (2016). 
[57] Y. Didi, B. Said, T. Cacciaguerra, K. L. Nguyen, V. Wernert, R. Denoyel, D. Cot, W. Sebai, M-P. Belleville, J. Sanchez-Marcano, F. Fajula, and A. Galarneau, Microporous Mesoporous Mater., (2019) in pres.

[58] R. Kohms, C.P. Haas, A. Hötzel, C. Splith, D. Enke, and U. Tallarek, React. Chem. Eng. 3, 353 (2018). 